\title{
Preparation of Pd/C by Atmospheric-Pressure Ethanol Cold Plasma and Its Preparation Mechanism
}

\author{
Zhuang Li, Jingsen Zhang, Hongyang Wang, Zhihui Li, Xiuling Zhang * ${ }^{-10}$ and Lanbo Di * \\ College of Physical Science and Technology, Dalian University, Dalian 116622, China; \\ lizhuang668@sina.com (Z.L.); 18742089936@163.com (J.Z.); hywang68@sina.com (H.W.); lee6062@163.com (Z.L.) \\ * Correspondence: xiulz@sina.com (X.Z.); dilanbo@163.com (L.D.); Tel.: +86-411-87402712 (X.Z. \& L.D.)
}

Received: 19 September 2019; Accepted: 3 October 2019; Published: 10 October 2019

\begin{abstract}
Treatment with atmospheric-pressure (AP) hydrogen cold plasma is an effective method for preparing highly active supported metal catalytic materials. However, this technique typically uses $\mathrm{H}_{2}$ as working gas, which is explosive and difficult to transport. This study proposes the use of $\mathrm{PdCl}_{2}$ as a $\mathrm{Pd}$ precursor and activated carbon as the support to fabricate $\mathrm{Pd} / \mathrm{C}$ catalytic materials (Pd/C-EP-Ar) by using ethanol — which is renewable, easily stored, and safe-combined with AP cold plasma (AP ethanol cold plasma) followed by calcination in Ar gas at $550{ }^{\circ} \mathrm{C}$ for $2 \mathrm{~h}$. Both Pd/C-EP and $\mathrm{Pd} / \mathrm{C}-\mathrm{HP}$ fabricated using AP ethanol and hydrogen cold plasma (without calcination in Ar gas) respectively, exhibit low CO oxidation reactivity. The activity of $\mathrm{Pd} / \mathrm{C}-\mathrm{EP}$ is lower than $\mathrm{Pd} / \mathrm{C}-\mathrm{HP}$, which is mainly ascribed to the carbon layer formed by ethanol decomposition during plasma treatment. However, the $100 \%$ CO conversion temperature $\left(T_{100}\right)$ of $\mathrm{Pd} / \mathrm{C}-\mathrm{EP}-\mathrm{Ar}$ is $140{ }^{\circ} \mathrm{C}$, which is similar to that of Pd/C-HP-Ar fabricated using AP hydrogen cold plasma (calcined in Ar gas at $550{ }^{\circ} \mathrm{C}$ for $2 \mathrm{~h}$ ). The characterization results of $\mathrm{X}$-ray diffraction, $\mathrm{X}$-ray photoelectron spectroscopy, and transmission electron microscopy indicated that the carbon layer formed by ethanol decomposition enhanced the interaction of metal nanoparticles to the support, and a high $\mathrm{Pd} / \mathrm{C}$ atomic ratio was obtained. This was beneficial to the high $\mathrm{CO}$ oxidation performance. This work provides a safe method for synthesizing high-performance $\mathrm{Pd} / \mathrm{C}$ catalytic materials avoiding the use of $\mathrm{H}_{2}$, which is explosive and difficult to transport.
\end{abstract}

Keywords: ethanol cold plasma; hydrogen cold plasma; $\mathrm{Pd} / \mathrm{C}$; $\mathrm{CO}$ oxidation; preparation mechanism

\section{Introduction}

Supported Pd catalytic materials are widely used in organic catalytic hydrogenation, CO oxidation, automobile exhaust treatment, and the Suzuki reaction, among others [1-6]. Thus, they have drawn interest for their potential use in the fabrication of supported Pd catalytic materials with high metal utilization, high activity, and long service life by using efficient, safe, simple, and low-cost methods. Although traditional impregnation, ion exchange, sol-gel, and vapor deposition methods can be applied to prepare highly active Pd catalytic materials, the fabrication process is generally complex and difficult to control [7-10]. Atmospheric-pressure (AP) cold plasma treatment is a fast and effective method for preparing metal catalytic materials with small metal nanoparticles and high activity. Owing to these properties, the aforementioned approach has been broadly applied in the fabrication of Pd catalytic materials [11-14].

As a non-equilibrium plasma, $\mathrm{H}_{2}$ or $\mathrm{NH}_{3}, \mathrm{CH}_{4}$ has been added into the working gas in AP cold plasma due to the frequency of collision between its electrons and heavy particles, leading to inadequate electron temperature for direct metal ion reduction [15-18]. Metal ions on the support were reduced to their metallic states by the generated active hydrogen species $\left(\mathrm{H}^{*}, \mathrm{H}_{2}{ }^{*}\right.$, etc. $)$ in AP cold plasma. However, the aforementioned gases are explosive and are difficult to store and transport. 
Thus, the development of a relatively safe AP cold plasma for the preparation of supported metal catalytic materials bears research significance and exhibits application potential.

Ethanol, a hydrogen-rich renewable resource, can be mixed with water in any proportion and shows reducibility. Research on reforming hydrogen production from ethanol has recently gained interest [19-21]. Plasma technology has been used to reform hydrogen production from ethanol. Wang et al. used microwave plasma $(2.45 \mathrm{GHz})$ to produce hydrogen from low carbon alcohol (methanol and ethanol) solutions and evaluated the effect of microwave power input and alcohol concentration on hydrogen production. Results indicated that not only hydrogen but carbon species (such as acetylene, $\mathrm{CO}$ and $\mathrm{CO}_{2}$ ) as well are produced during microwave discharge [22]. Wu et al. reported on the synthesis of a $\mathrm{Ni} / \gamma-\mathrm{Al}_{2} \mathrm{O}_{3}$ catalyst by dielectric barrier discharge, which increased the conversion rate of ethanol to hydrogen by nearly $30 \%$, meanwhile, the carbon balance was $97 \%$ [23].

In a previous study, metal (Au, Pd, Ag, Pt) ions loaded on Deggusa P25 (commercial titania) were successfully reduced by combining AP cold plasma with ethanol instead of $\mathrm{H}_{2}$, and Pd/P25 catalytic materials with high activity and small Pd nanoparticles were prepared by AP ethanol cold plasma treatment. The performance was better than that of the catalytic materials prepared using AP hydrogen cold plasma $[24,25]$. The structure, specific surface area, and other properties of supports influence the catalytic materials, thus, supports play an important role in these materials. Activated carbon has been widely used as a support because of its high-specific surface area $\left(500-1700 \mathrm{~m}^{2} \cdot \mathrm{g}^{-1}\right)$ and rich oxygen-containing functional groups located on the surface. In addition, activated carbon is cheap and conducive to the recovery of precious metals. In this study, activated carbon was selected as the support, and AP ethanol cold plasma was used in the fabrication of $\mathrm{Pd} / \mathrm{C}$ catalytic materials.

In this study, $\mathrm{Pd} / \mathrm{C}$ catalytic materials were successfully prepared using AP ethanol cold plasma. The results of transmission electron microscopy (TEM), X-ray photoelectron spectroscopy (XPS), $\mathrm{X}$-ray diffraction (XRD), and CO oxidation reaction show that the CO oxidation activity of Pd/C-EP-Ar prepared using AP ethanol cold plasma is similar to that of Pd/C-HP-Ar prepared using AP hydrogen cold plasma. A carbon protective layer can be formed during AP ethanol cold plasma preparation, which can effectively protect the Pd nanoparticles.

\section{Experimental}

\subsection{Catalysts Preparation}

Activated carbon (40-60 mesh, Beijing Guanghua Timber Mill., Beijing, China) was used as the support, and the aqueous solution of $\mathrm{PdCl}_{2}$ (AR, 99\%, Tianjin Kemio Chemical Reagent Co., Ltd., Tianjin, China) was used as the Pd source. Prior to the fabrication of Pd/C catalytic materials, the activated carbon and $30 \mathrm{wt} \% \mathrm{HNO}_{3}$ were mixed in a $250 \mathrm{~mL}$ conical flask and then stored in a constant-temperature water bath at $85^{\circ} \mathrm{C}$ for $5 \mathrm{~h}$. The mixture was washed with deionized water to neutral $\mathrm{pH}$ and then dried at $120^{\circ} \mathrm{C}$ for $2 \mathrm{~h}$ for subsequent use [26,27]. The $\mathrm{Pd} / \mathrm{C}$ (theoretical load of $\mathrm{Pd}$ $=5 \mathrm{wt} \%$ ) precursor was prepared using the treated activated carbon impregnated in a $\mathrm{PdCl}_{2}$ solution for $12 \mathrm{~h}$ and then dried at $120^{\circ} \mathrm{C}$ for $2 \mathrm{~h}$. The $\mathrm{Pd} / \mathrm{C}$ precursor was ultimately treated with AP ethanol cold plasma to prepare $\mathrm{Pd} / \mathrm{C}$ catalytic materials.

The schematic of the $\mathrm{Pd} / \mathrm{C}$ catalytic materials prepared using the AP ethanol cold plasma experimental device is presented in Figure 1. Plasma discharge was powered by a low-temperature plasma power (CTP-2000 K, Nanjing Suman Electronic Co. Ltd., Nanjing, China) at a $36 \mathrm{kV}$ peak-to-peak discharge voltage of sinusoidal alternating current and a frequency of $13.4 \mathrm{kHz}$. A plate-to-plate type quartz reactor was placed between two parallel electrodes with a diameter of $50 \mathrm{~mm}$ and a discharge gap of $4 \mathrm{~mm}$. Ethanol in a bubbler reactor in a $25{ }^{\circ} \mathrm{C}$ thermostatic bath was carried by 100 standard cubic centimeters per minute (SCCM) of Ar gas as the working gas. The partial pressure of ethanol was approximately $7.99 \mathrm{kPa}$, calculated using the saturated vapor pressure of ethanol. Treatment with AP ethanol cold plasma was conducted five times (at a discharge interval of $10 \mathrm{~min}$ ) for 2 min each treatment. The $\mathrm{Pd} / \mathrm{C}$ precursor treated with AP ethanol cold plasma is denoted as 
Pd/C-EP. For comparison, a Pd/C-HP sample was also prepared using AP hydrogen cold plasma with a mixture of $\mathrm{Ar}$ and $\mathrm{H}_{2}$ at $50 \mathrm{SCCM}$ each, the mixture was used as the working gas. After calcination in 100 SCCM of Ar gas at $550{ }^{\circ} \mathrm{C}$ for $2 \mathrm{~h}, \mathrm{Pd} / \mathrm{C}-\mathrm{EP}$ and Pd/C-HP are denoted as Pd/C-EP-Ar and $\mathrm{Pd} / \mathrm{C}-\mathrm{HP}-\mathrm{Ar}$, respectively.

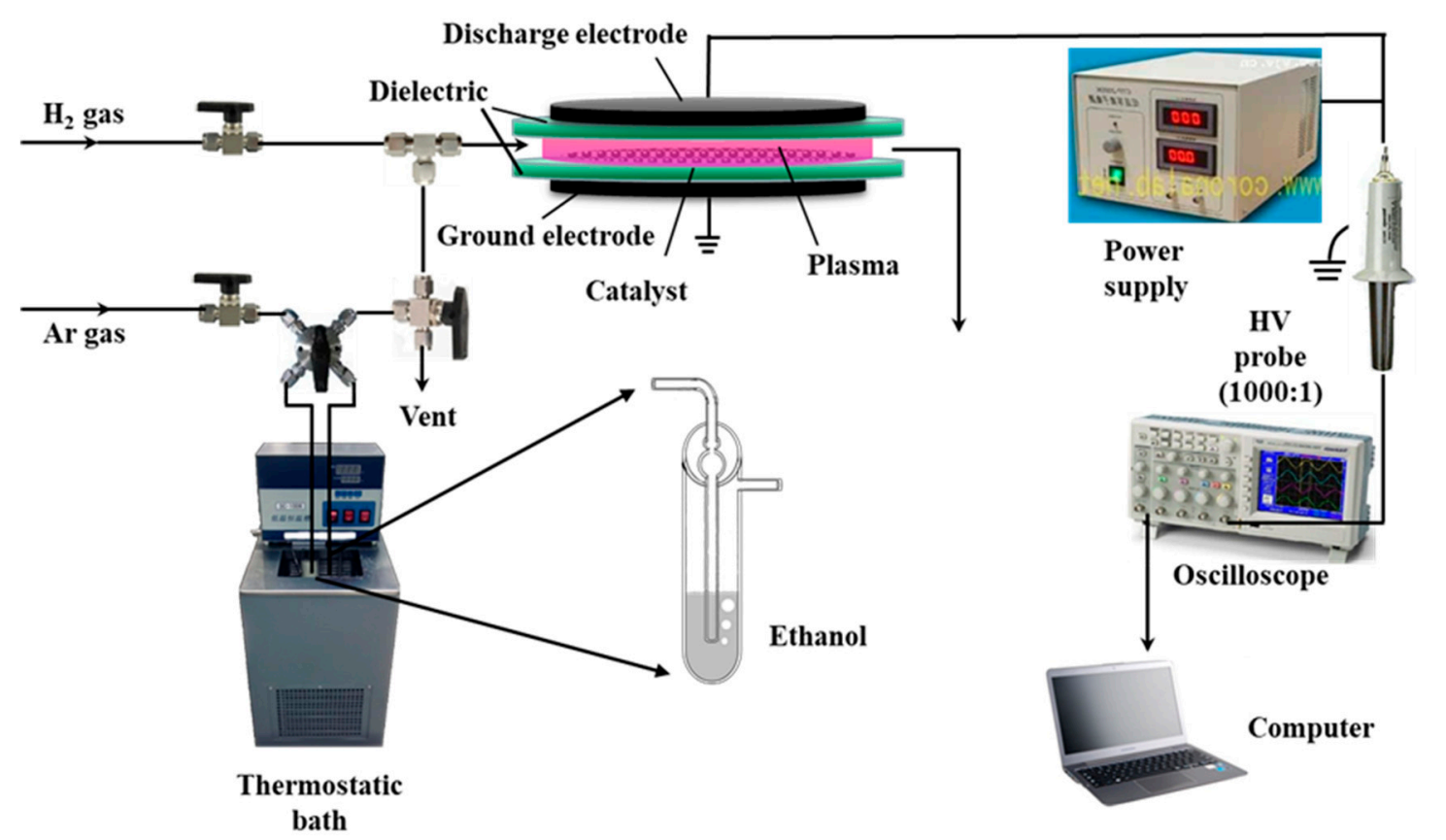

Figure 1. Schematic of atmospheric-pressure ethanol cold plasma treatment for the preparation of $\mathrm{Pd} / \mathrm{C}$ catalytic materials.

\subsection{Catalysts Characterization and Activity Test}

The samples were characterized by XRD (DX-2700, Dandong Haoyuan Instrument Co., Ltd., Dandong, China) with graphite-monochromatized $\mathrm{Cu} K \alpha$ radiation $(\lambda=1.54178 \AA)$ under the following conditions: Voltage, $40 \mathrm{kV}$; current, $30 \mathrm{~mA}$; scan range, $5^{\circ}$ to $90^{\circ}$. The chemical compositions and binding energies of the samples were investigated by XPS (ESCALAN-250, Thermo VG, Waltham, MA, USA) with a monochromatized $\mathrm{Al} \mathrm{K} \alpha(1486.6 \mathrm{eV})$ X-ray source. All binding energies were corrected with C1s orbital binding energies at $284.6 \mathrm{eV}$. The morphology of the sample was investigated by TEM (HT7700, Hitachi Company, Tokyo, Japan), and the average size of the Pd nanoparticles was determined by selecting at least 200 nanoparticles. The specific surface area, pore volume, and pore size of the materials were measured using a NOVA 2200e gas sorption analyzer (Quantachrome Company, Boynton Beach, FL, USA) via nitrogen adsorption and desorption. CO oxidation was selected as a probe reaction to evaluate the activity of the prepared $\mathrm{Pd} / \mathrm{C}$ catalytic materials in a quartz tube (inner diameter: $4 \mathrm{~mm}$ ) placed in a temperature-programmed furnace. Detailed test conditions can be found in previous work [26].

\section{Results and Discussion}

Figure 2 presents the $\mathrm{CO}$ oxidation reactivity of the $\mathrm{Pd} / \mathrm{C}$ samples prepared by $\mathrm{AP}$ ethanol and hydrogen cold plasma. The $100 \% \mathrm{CO}$ conversion temperature $\left(T_{100}\right)$ of Pd/C-EP-Ar, Pd/C-HP-Ar, and $\mathrm{Pd} / \mathrm{C}$-HP were $140{ }^{\circ} \mathrm{C}, 130^{\circ} \mathrm{C}$, and $215^{\circ} \mathrm{C}$, respectively. Notably, no CO oxidation activity over $\mathrm{Pd} / \mathrm{C}$-EP was observed even at $200{ }^{\circ} \mathrm{C}$, and the conversion rate of $\mathrm{CO}$ at $230{ }^{\circ} \mathrm{C}$ was only $14.5 \%$. The significantly lower CO oxidation reactivity over Pd/C-EP than that over Pd/C-HP is mainly attributed to the carbon layer formed by ethanol decomposition during plasma treatment, which will be discussed later. The results show that the $T_{100}$ of Pd/C-EP-Ar is similar to the $T_{100}$ of Pd/C-HP-Ar, indicating that AP ethanol cold plasma can achieve the same effect and ability as that of AP hydrogen 
cold plasma in the preparation of $\mathrm{Pd} / \mathrm{C}$ catalytic materials, and its advantage is that the use of explosive $\mathrm{H}_{2}$ gas is prevented. In this work, the theoretical load of $\mathrm{Pd}$ is $5 \mathrm{wt} \%$. The $T_{100}$ of $\mathrm{Pd} / \mathrm{C}-\mathrm{EP}-\mathrm{Ar}\left(140{ }^{\circ} \mathrm{C}\right)$ is close to the previously reported $6 \mathrm{wt} \% \mathrm{Pd} /$ graphene $\left(127^{\circ} \mathrm{C}\right)$ fabricated by the thermal reduction method [3].

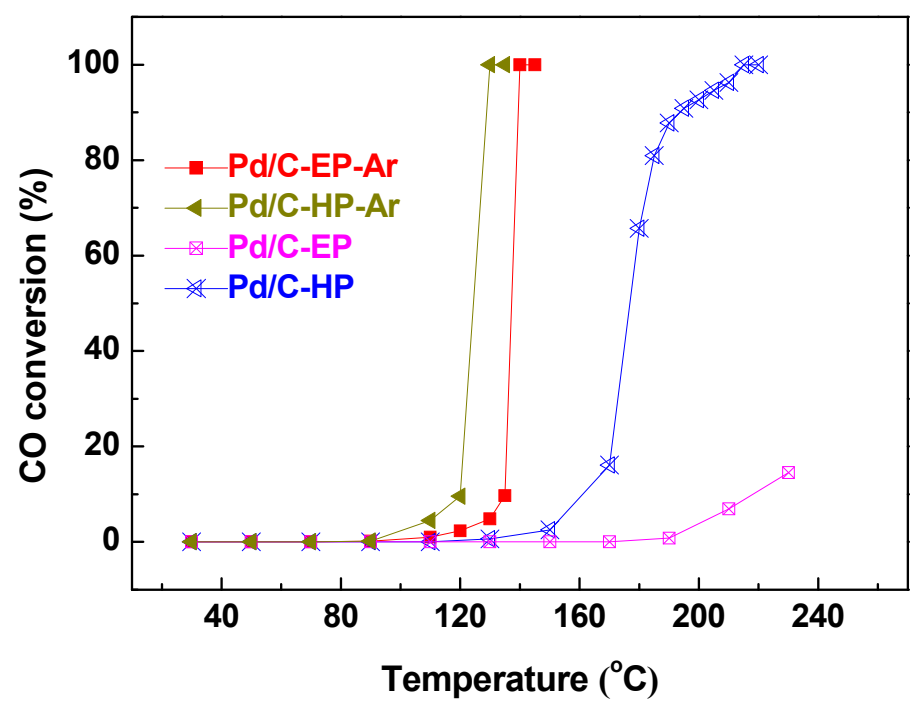

Figure 2. Catalytic activity of the catalytic materials Pd/C-EP-Ar, Pd/C-HP-Ar, Pd/C-EP, and Pd/C-HP for CO oxidation.

The XRD patterns of the Pd/C-EP, Pd/C-EP-Ar, Pd/C-HP, Pd/C-HP-Ar, and Pd/C precursor are illustrated in Figure 3. The broad diffraction peaks at ca. $23^{\circ}, 44^{\circ}$ and $80^{\circ}$ of all samples corresponded to the (002), (100) and (111) planes of graphitic carbon structure of the support [28]. These peaks are weak and broad, revealing a poor crystallite graphitic structure. Meanwhile, the characteristic diffraction peaks of Pd/C-EP-Ar and Pd/C-HP-Ar at $40.1^{\circ}, 46.6^{\circ}, 68.1^{\circ}$, and $82.4^{\circ}$ corresponded to the (111), (200), (220), and (311) planes of metal Pd (JCPDS\#46-1043), respectively. However, the Pd peaks for Pd/C-EP and Pd/C-HP were weaker than those of Pd/C-EP-Ar and Pd/C-HP-Ar, only the Pd peak at $40.1^{\circ}$ was observed. The diffraction peak of $\mathrm{Pd} / \mathrm{C}-\mathrm{EP}$ at $25.0^{\circ}$ was stronger than that of the support and other samples. This difference may be attributed to the carbon species formed on the material surface by ethanol decomposition during plasma discharge. Pd in Pd/C-EP-Ar and Pd/C-HP-Ar showed strong and sharp peaks, indicating that the nanoparticle size of $\mathrm{Pd}$ was relatively large owing to the agglomeration of Pd nanoparticles. Such agglomeration resulted from calcination at high temperatures in Ar gas.

To evaluate the effect of plasma treatment on the pore structure of the $\mathrm{Pd} / \mathrm{C}$ catalytic materials, the $\mathrm{N}_{2}$ adsorption and desorption and pore size distribution of all samples were observed (Figure 4). The specific surface area, pore diameter, and pore volume of the $\mathrm{Pd} / \mathrm{C}$ samples are summarized in Table 1 . The $\mathrm{Pd} / \mathrm{C}$ catalytic materials in descending order of specific surface area were $\mathrm{Pd} / \mathrm{C}-\mathrm{EP}-\mathrm{Ar}>$ $\mathrm{Pd} / \mathrm{C}-\mathrm{HP}-\mathrm{Ar}>\mathrm{Pd} / \mathrm{C}-\mathrm{HP}>\mathrm{Pd} / \mathrm{C}-\mathrm{EP}>\mathrm{Pd} / \mathrm{C}$ with the corresponding specific surface areas of 874, 871, 736,703 , and $690 \mathrm{~m}^{2} \cdot \mathrm{g}^{-1}$, respectively (Figure $4 \mathrm{a} \&$ Table 1 ). Correspondingly, the pore volumes of the $\mathrm{Pd} / \mathrm{C}-\mathrm{EP}-\mathrm{Ar}$ and $\mathrm{Pd} / \mathrm{C}-\mathrm{HP}-\mathrm{Ar}$ samples increased to 0.50 and $0.47 \mathrm{~cm}^{3} \cdot \mathrm{g}^{-1}$, respectively. Compared to $\mathrm{Pd} / \mathrm{C}-\mathrm{HP}$ and $\mathrm{Pd} / \mathrm{C}-\mathrm{EP}$, the specific surface area and pore volume of the Pd/C-EP-Ar and Pd/C-HP-Ar samples were increased, which may be mainly ascribed to the removal of the unstable carbon species in the presence of active Pd species during calcination.

XPS analysis was conducted to further investigate the valence states of the $\mathrm{Pd} / \mathrm{C}$ catalytic materials, and the XPS spectra of Pd3d, Cl2p and C1s were measured (Figure 5). The peaks of $\mathrm{Pd}_{3 / 2}$ in all samples can be divided into three peaks at $335.3,335.9$, and $337.5 \mathrm{eV}$, which correspond to $\mathrm{Pd}^{0}, \mathrm{Pd}^{2+}$, and $\mathrm{Pd}^{4+}$, respectively $[14,29]$. The contents of the different valence states of $\mathrm{Pd}$ in the $\mathrm{Pd} / \mathrm{C}$ catalytic materials were calculated based on the XPS spectra of Pd 3d (Table 2). The Pd/C atomic ratios in 
Pd/C-HP (0.026) was higher than that in Pd/C-HP-Ar (0.010) prepared by calcination. This difference was attributed to the active hydrogen species and high-energy electrons induced by AP hydrogen cold plasma treatment. Owing to these species, the Pd ions in the support channel were reduced and transferred to the surface, resulting in higher content of surface Pd components in Pd/C-HP [30]. In addition, there is a strong interaction between the Pd species and oxygen-containing functional groups on the surface of the support. Therefore, the Pd nanoparticles agglomerated and migrated back to the pore channels during calcination, resulting in a decrease in surface Pd in Pd/C-HP-Ar. Notably, a lower $\mathrm{Pd} / \mathrm{C}$ atomic ratio in $\mathrm{Pd} / \mathrm{C}$-EP (0.013) was observed due to the protection of the carbon layer formed by ethanol decomposition during plasma treatment. However, it was increased to 0.023 for Pd/C-EP-Ar after calcination. The reason may be attributed to the destruction of the carbon layer at a high temperature, which led to the exposure of more Pd species than the as-prepared Pd/C-EP catalytic material. This is consistent with the XRD results, which indicated that the broad peak corresponding to carbon species in Pd/C-EP-Ar was obviously decreased compared to that for Pd/C-EP.

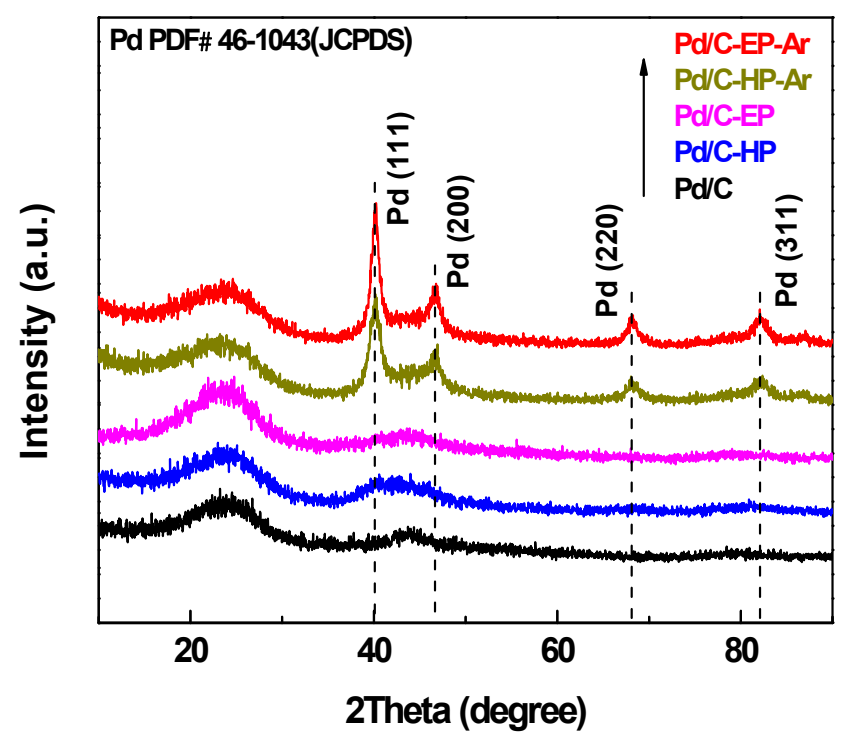

Figure 3. X-ray diffraction (XRD) patterns of Pd/C-EP-Ar, Pd/C-HP-Ar, Pd/C-EP, Pd/C-HP, and Pd/C.
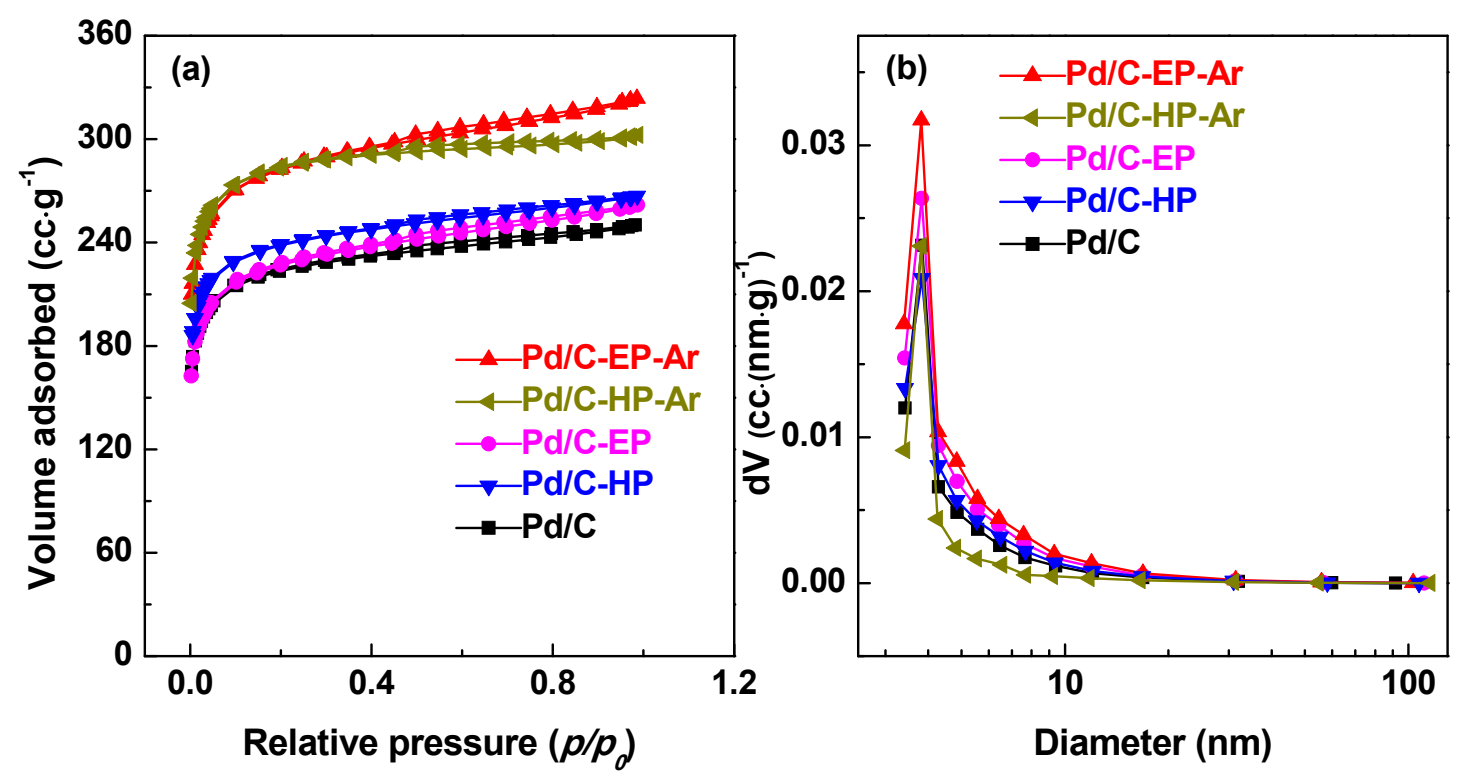

Figure 4. (a) $\mathrm{N}_{2}$ adsorption-desorption isotherms and (b) pore size distributions of $\mathrm{Pd} / \mathrm{C}-\mathrm{EP}-\mathrm{Ar}$, $\mathrm{Pd} / \mathrm{C}-\mathrm{HP}-\mathrm{Ar}, \mathrm{Pd} / \mathrm{C}-\mathrm{EP}, \mathrm{Pd} / \mathrm{C}-\mathrm{HP}$, and Pd/C. 
Table 1. Specific surface area, pore diameter, and pore volume of the $\mathrm{Pd} / \mathrm{C}$ catalytic materials.

\begin{tabular}{cccc}
\hline Samples & Pore Diameter $(\mathbf{n m})$ & Pore Volume $\left(\mathbf{c m}^{\mathbf{3}} \cdot \mathbf{g}^{-\mathbf{1}}\right)$ & Specific Surface Area $\left(\mathbf{m}^{\mathbf{2}} \cdot \mathbf{g}^{-\mathbf{1}}\right)$ \\
\hline Pd/C-EP-Ar & 3.82 & 0.50 & 874 \\
Pd/C-HP-Ar & 3.82 & 0.47 & 871 \\
Pd/C-EP & 3.83 & 0.41 & 703 \\
Pd/C-HP & 3.83 & 0.41 & 736 \\
Pd/C & 3.84 & 0.39 & 690 \\
\hline
\end{tabular}
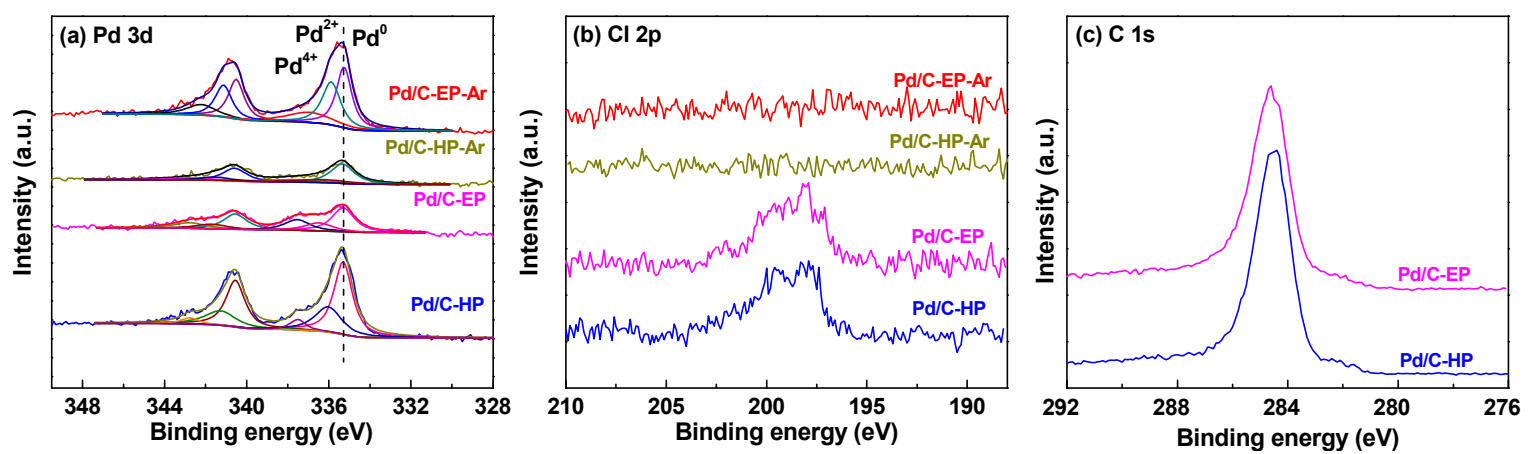

Figure 5. X-ray photoelectron spectroscopy (XPS) spectra of (a) $\mathrm{Pd} 3 \mathrm{~d}$ and (b) $\mathrm{Cl} 2 \mathrm{p}$ in $\mathrm{Pd} / \mathrm{C}-\mathrm{EP}-\mathrm{Ar}$, $\mathrm{Pd} / \mathrm{C}-\mathrm{HP}-\mathrm{Ar}, \mathrm{Pd} / \mathrm{C}-\mathrm{EP}$ and Pd/C-HP, as well as (c) C1s XPS spectra in Pd/C-EP and Pd/C-HP.

Table 2. $\mathrm{Pd}$ composition and $\mathrm{Pd} / \mathrm{C}$ atomic ratios in the $\mathrm{Pd} / \mathrm{C}$ catalytic materials.

\begin{tabular}{ccccc}
\hline \multirow{2}{*}{ Catalyst } & \multicolumn{3}{c}{ Pd Composition (\%) } & \multirow{2}{*}{ Pd/C Atomic Ratio } \\
\cline { 2 - 4 } & $\mathbf{P d}^{\mathbf{0}}$ & $\mathbf{P d}^{\mathbf{2 +}}$ & $\mathbf{P d}^{\mathbf{4 +}}$ & \\
\hline Pd/C-EP-Ar & 42.6 & 36.2 & 21.2 & 0.023 \\
Pd/C-HP-Ar & 58.7 & 19.8 & 21.5 & 0.010 \\
Pd/C-EP & 52.1 & 21.4 & 26.5 & 0.013 \\
Pd/C-HP & 61.4 & 31.1 & 7.5 & 0.026 \\
\hline
\end{tabular}

In Figure $5 b$, the characteristic peak of $\mathrm{Cl} 2 \mathrm{p}$ is observed in the range of $190 \mathrm{eV}$ to $210 \mathrm{eV}$ for both $\mathrm{Pd} / \mathrm{C}-\mathrm{EP}$ and Pd/C-HP, meanwhile, no such peak is found in Pd/C-EP-Ar and Pd/C-HP-Ar, which may be attributed to the removal of chlorine ions by calcination under Ar gas at $550{ }^{\circ} \mathrm{C}$ [27]. The chlorine ions largely influence the activity of supported metal catalytic materials [31-34]. The $T_{100}$ values of $\mathrm{Pd} / \mathrm{C}-\mathrm{EP}$ and $\mathrm{Pd} / \mathrm{C}-\mathrm{HP}$ were higher than those of Pd/C-EP-Ar and Pd/C-HP-Ar because of the presence of $\mathrm{Cl}^{-}$in the samples. The XPS analysis results of $\mathrm{Cl} 2 \mathrm{p}$ also corresponded to the activity results of the $\mathrm{Pd} / \mathrm{C}$ catalytic materials on $\mathrm{CO}$ oxidation reactivity.

Figure $5 \mathrm{c}$ presents the C1s XPS spectra in Pd/C-EP and Pd/C-HP. The binding energy at $284.6 \mathrm{eV}$ for the samples is ascribed to the adventageous carbon or graphite carbon. Compared to Pd/C-HP, there is a new weak peak at ca. $285.5 \mathrm{eV}$, attributing to the amorphous carbon layer formed by ethanol decomposition during plasma treatment. This phenomenon is also obtained by using AP CO cold plasma to reduce the metal ions supported on $\mathrm{TiO}_{2}$ support [35].

As shown in Table 2, the proportions of metal $\mathrm{Pd}^{0}$ on the surfaces of $\mathrm{Pd} / \mathrm{C}-\mathrm{HP}$ and $\mathrm{Pd} / \mathrm{C}-\mathrm{EP}$ are $61.4 \%$ and $52.1 \%$ respectively, and those of Pd/C-HP-Ar and Pd/C-EP-Ar prepared by calcination in $\mathrm{Ar}$ gas are $58.7 \%$ and $42.6 \%$, respectively. The proportions of $\mathrm{Pd}^{0}$ decreased after calcination, considering the oxidation of the Pd nanoparticles by the oxygen-containing functional groups on the support surface at high-temperature calcination. The catalytic activity of a material is related to its Pd content. $\mathrm{Pd} / \mathrm{C}-\mathrm{HP}$ and $\mathrm{Pd} / \mathrm{C}-\mathrm{EP}$, which contained large amounts of $\mathrm{Pd}^{0}$, exhibited significantly lower activity, compared with $\mathrm{Pd} / \mathrm{C}-\mathrm{HP}-\mathrm{Ar}$ and $\mathrm{Pd} / \mathrm{C}-\mathrm{EP}-\mathrm{Ar}$, which contained small amounts of $\mathrm{Pd}^{0}$, because of the influence of $\mathrm{Cl}^{-}$ions on the materials. 
Figure 6 shows the TEM images and the Pd nanoparticle size distribution in the Pd/C catalytic materials. $\mathrm{Pd} / \mathrm{C}-\mathrm{EP}, \mathrm{Pd} / \mathrm{C}-\mathrm{EP}-\mathrm{Ar}, \mathrm{Pd} / \mathrm{C}-\mathrm{HP}$, and Pd/C-HP-Ar had average Pd nanoparticle sizes of $2.4 \pm 0.5,11.5 \pm 3.8,3.7 \pm 1.2$, and $10.6 \pm 2.3 \mathrm{~nm}$ respectively, which were consistent with the XRD results. The Pd nanoparticles for Pd/C-EP and Pd/C-HP were smaller and uniformly dispersed on the surface of the support, which conformed to the characteristics of supported metal catalysts prepared using AP cold plasma [25-27,29]. Pd/C-EP had the smallest Pd nanoparticles because of the carbon layer formed by ethanol decomposition, which can protect the Pd nanoparticles and inhibit their aggregation. The Pd nanoparticles agglomerated when the materials were calcined at a high temperature, resulting in larger Pd nanoparticles in Pd/C-EP-Ar and Pd/C-HP-Ar. In addition, the sizes and distribution of the Pd nanoparticles in Pd/C-EP-Ar were not uniform because of the destruction of the carbon layer caused by high-temperature calcination and uneven agglomeration of $\mathrm{Pd}$ nanoparticles. The results indicated that Pd ions loaded on activated carbon could be reduced using AP ethanol cold plasma. Moreover, the small Pd nanoparticles and uniform distribution in Pd/C-EP is attributed to the carbon layer protection, however, after calcination, Pd/C-EP-Ar had a larger Pd nanoparticle size. In spite of this, Pd/C-EP-Ar had similar average size of Pd nanoparticles with Pd/C-HP-Ar. Most importantly, explosive hydrogen gas is avoided for synthesizing the $\mathrm{Pd} / \mathrm{C}$ catalytic material.

The proposed preparation mechanisms of Pd/C-EP-Ar and Pd/C-HP-Ar were determined from the results of the XPS, TEM, and XRD analyses, among others (Figure 7). The interaction of $\mathrm{e}^{*}$ with ethanol during AP ethanol cold plasma treatment can induce not only the excited states of the Ar* by the collision of high-energy electrons ( $\left.\mathrm{e}^{*}\right)$ with Ar gas but also active hydrogen species $\left(\mathrm{H}_{1} \mathrm{H}^{*}, \mathrm{H}_{2}^{*}\right)$, both of which can reduce metal ions. Meanwhile, $\mathrm{CO}$ and the excited state of $\mathrm{CO}^{*}$ produced by ethanol decomposition can also reduce $\mathrm{Pd}$ ions, and the carbon layer generated by ethanol decomposition can inhibit the agglomeration of Pd nanoparticles. Thus, Pd/C-EP with the smallest Pd nanoparticles size was fabricated [24,25,35]. However, Pd/C-EP-Ar with large Pd nanoparticles was produced after high-temperature calcination in Ar gas to remove chlorine ions. Pd ions were reduced by the active hydrogen species $\left(\mathrm{H}, \mathrm{H}^{*}, \mathrm{H}_{2}{ }^{*}\right)$ in the preparation of AP hydrogen cold plasma. They are produced by high-energy electrons $\mathrm{e}^{*}$ colliding with $\mathrm{Ar}$ and $\mathrm{H}_{2}$ gases. Pd/C-HP-Ar with larger Pd nanoparticles can be formed when $\mathrm{Pd} / \mathrm{C}-\mathrm{HP}$ is calcined in Ar gas to remove chloride ions.

In summary, both AP ethanol cold plasma and AP hydrogen cold plasma can reduce the Pd ions into metallic Pd nanoparticles. The Pd/C-HP and Pd/C-EP catalytic materials exhibited significantly lower $\mathrm{CO}$ oxidation activity in spite of their large amounts of metallic $\mathrm{Pd}^{0}$. The low activity of $\mathrm{Pd} / \mathrm{C}-\mathrm{HP}$ is attributed to the influence of $\mathrm{Cl}^{-}$ions, while it is ascribed to the influence of $\mathrm{Cl}^{-}$ions and the protection of the carbon layer formed by ethanol decomposition in plasma for Pd/C-EP. In addition, the $\mathrm{Pd} / \mathrm{C}$ atomic ratio for Pd/C-EP (0.013) is lower than that for Pd/C-HP (0.026) due to the carbon layer protection. Therefore, $\mathrm{Pd} / \mathrm{C}$-EP exhibits lower $\mathrm{CO}$ oxidation reactivity than $\mathrm{Pd} / \mathrm{C}-\mathrm{HP}$. In contrast, both Pd/C-HP-Ar and Pd/C-EP-Ar exhibit high CO oxidation activity notwithstanding the large size of $\mathrm{Pd}$ nanoparticles due to the high-temperature calcination. Compared to the Pd/C-HP and Pd/C-EP catalytic materials, the enhanced performance of the Pd/C-HP-Ar and Pd/C-EP-Ar samples is mainly attributed to the removal of $\mathrm{Cl}^{-}$ions. In addition, the average size of $\mathrm{Pd}$ nanoparticles in $\mathrm{Pd} / \mathrm{C}-\mathrm{HP}-\mathrm{Ar}$ is smaller than that in $\mathrm{Pd} / \mathrm{C}-\mathrm{EP}-\mathrm{Ar}$, while the $\mathrm{Pd} / \mathrm{C}$ atomic ratio in $\mathrm{Pd} / \mathrm{C}-\mathrm{EP}-\mathrm{Ar}$ is higher than that in $\mathrm{Pd} / \mathrm{C}-\mathrm{HP}-\mathrm{Ar}$ due to the protection of the carbon layer. Therefore, both of them exhibit high $\mathrm{CO}$ oxidation activity. 

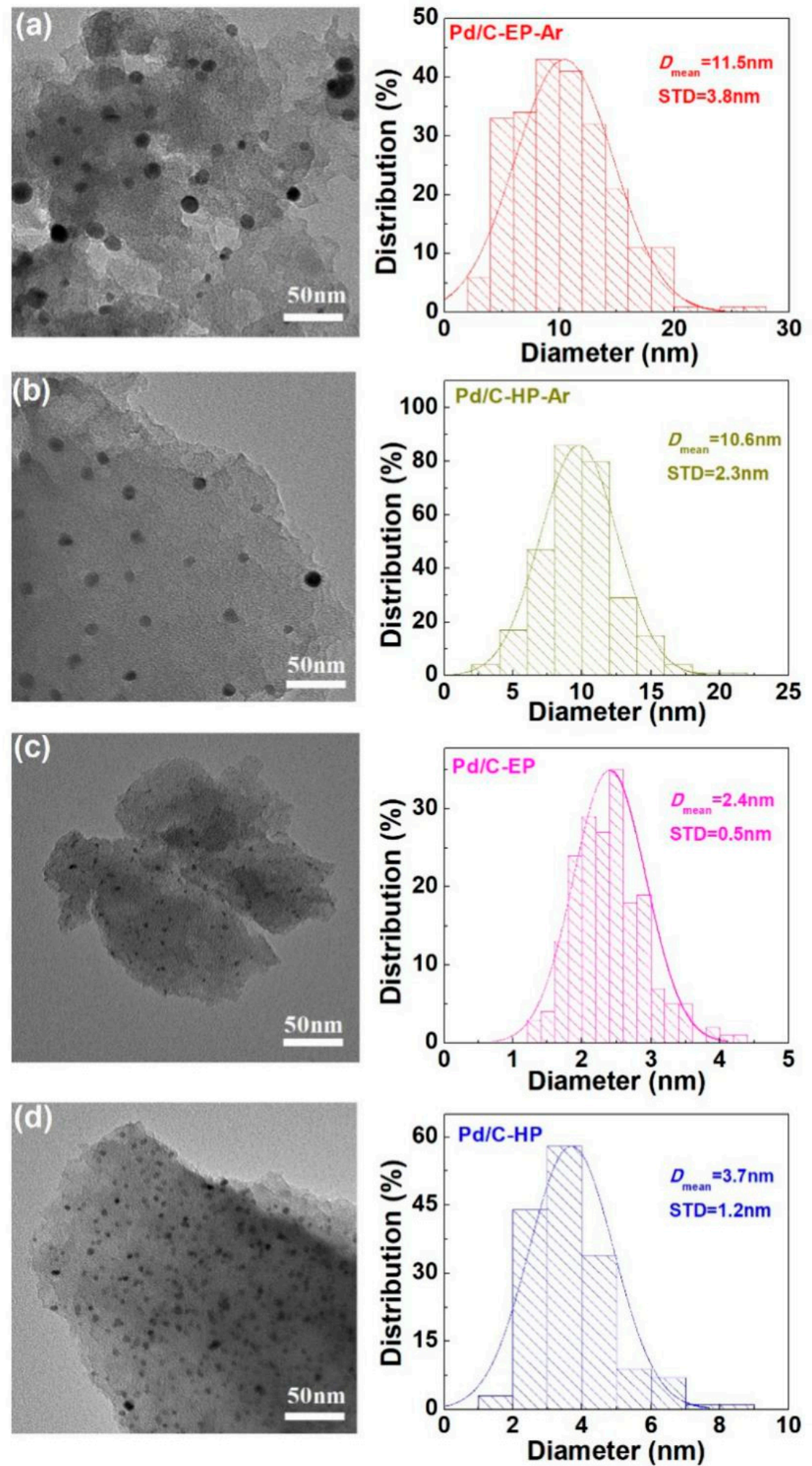

Figure 6. Typical transmission electron microscopy (TEM) images of (a) Pd/C-EP-Ar, (b) Pd/C-HP-Ar, (c) $\mathrm{Pd} / \mathrm{C}-\mathrm{EP}$, and (d) $\mathrm{Pd} / \mathrm{C}-\mathrm{HP}$ and the corresponding histograms of the size distribution of the Pd nanoparticles. 


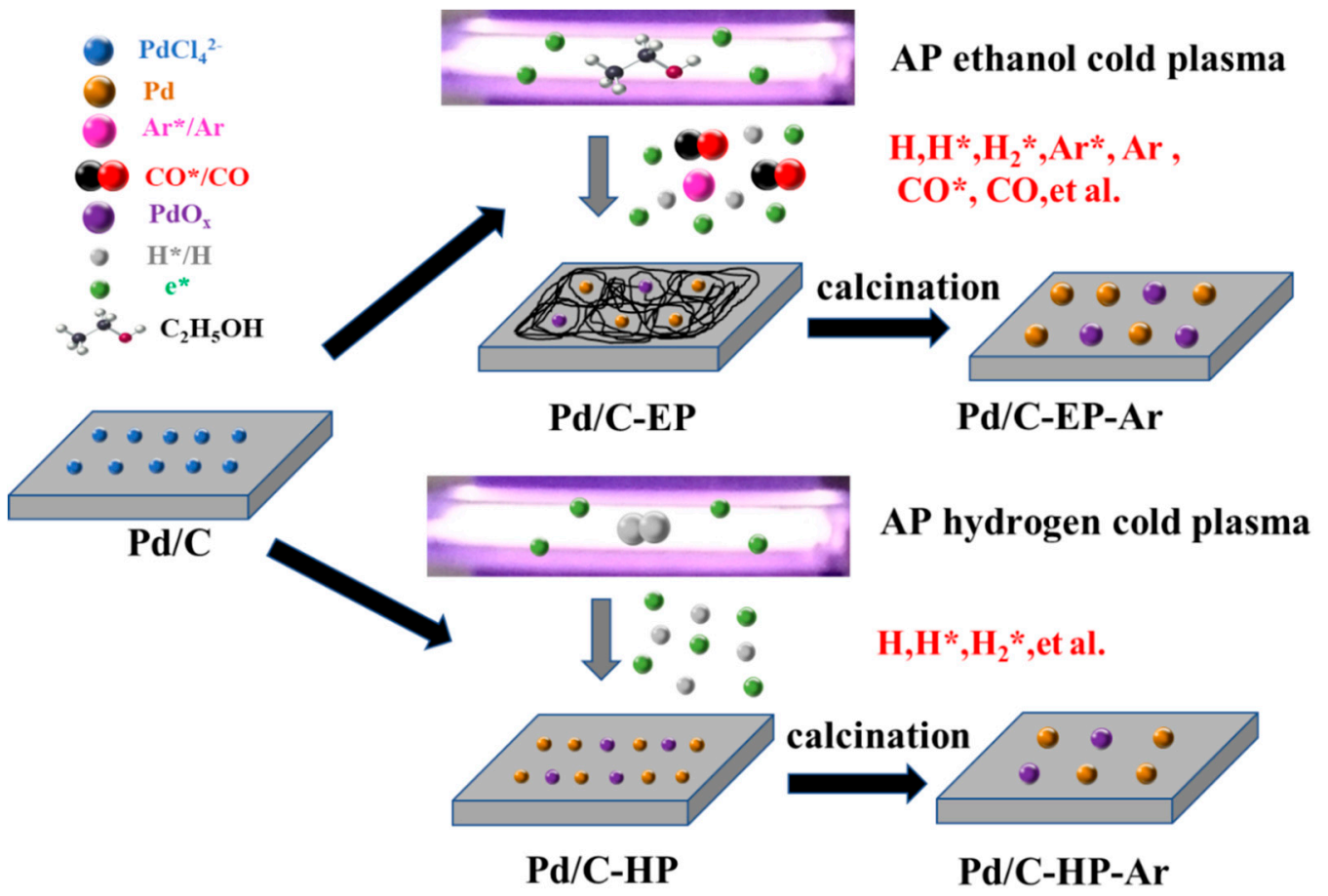

Figure 7. Schematic of the proposed preparation mechanism of Pd/C-EP-Ar and Pd/C-HP-Ar catalytic materials.

\section{Conclusions}

$\mathrm{Pd} / \mathrm{C}$ catalytic materials were prepared by treatment with AP ethanol cold plasma and AP hydrogen cold plasma. The structure and properties of the materials were characterized, and the preparation mechanism was investigated. The results of TEM, XPS, and XRD analyses show that both methods can reduce the Pd ions loaded on the activated carbon to the metal state. Not only the active hydrogen species but also reductive species, such as active $\mathrm{CO}^{*}$ species, can be formed during treatment with AP ethanol cold plasma. All of these species, produced by ethanol decomposition, can reduce the Pd ions. The Pd nanoparticles in Pd/C-EP were smaller than those in Pd/C-HP because of the carbon layer formed via ethanol decomposition, which effectively prevented the agglomeration of Pd nanoparticles. The results of CO oxidation reaction indicated that the $100 \%$ CO conversion temperature $\left(T_{100}\right)$ of $\mathrm{Pd} / \mathrm{C}$-EP-Ar is $140{ }^{\circ} \mathrm{C}$, which was similar to that of $\mathrm{Pd} / \mathrm{C}-\mathrm{HP}$-Ar prepared using AP hydrogen cold plasma. AP ethanol cold plasma and AP hydrogen plasma can be effectively used to fabricate $\mathrm{Pd} / \mathrm{C}$ catalytic materials. The use of $\mathrm{H}_{2}$, which is explosive and difficult to transport, was avoided in the treatment with AP ethanol cold plasma. This study carries considerable research significance and application potential for the fabrication of supported metal catalytic materials.

Author Contributions: Conceptualization, L.D. and X.Z.; Data curation, Z.L., J.Z. and Z.L.; Investigation, Z.L. and H.W.; Project administration, L.D.; Supervision, L.D. and X.Z.; Writing-original draft, Z.L. and J.Z.; Writing_review \& editing, X.Z and L.D.

Funding: This research was funded by National Natural Science Foundation of China (Grant Nos. 21773020, 21673026, 11505019), Liaoning Innovative Talents in University (Grant No. LR2017025), Natural Science Foundation of Liaoning Province (Grant No. 20180550085), Graduate Education and Teaching Reform Fund of Dalian University, and the Innovation and entrepreneurship training program for college students of Dalian University (Grant No. 201911258364).

Conflicts of Interest: The authors declare no conflict of interest. 


\section{References}

1. Fihri, A.; Cha, D.; Bouhrara, M.; Almana, N.; Polshettiwar, V. Fibrous nano-silica (KCC-1) -supported palladium catalyst: Suzuki coupling reactions under sustainable conditions. ChemSusChem 2012, 5, 85-89. [CrossRef]

2. Zeng, M.F.; Zhang, X.; Shao, L.J.; Qi, C.Z.; Zhang, X.M. Highly porous chitosan microspheres supported palladium catalyst for coupling reactions in organic and aqueous solutions. J. Organomet. Chem. 2012, 704, 29-37. [CrossRef]

3. Li, Y.Z.; Yu, Y.; Wang, J.G.; Song, J.; Li, Q.; Dong, M.D.; Liu, C.J. CO oxidation over graphene supported palladium catalyst. Appl. Catal. B Environ. 2012, 125, 189-196. [CrossRef]

4. Monguchi, Y.; Wakayama, F.; Ueda, S.; Ito, R.; Takada, H.; Inoue, H.; Nakamura, A.; Sawama, Y.; Sajiki, H. Amphipathic monolith-supported palladium catalysts for chemoselective hydrogenation and cross-coupling reactions. RSC Adv. 2017, 7, 1833-1840. [CrossRef]

5. Blaser, H.U.; Indolese, A.; Schnyder, A.; Steiner, H.; Studer, M. Supported palladium catalysts for fine chemicals synthesis. J. Mol. Catal. A Chem. 2001, 173, 3-18. [CrossRef]

6. Zhao, F.Y.; Bhanage, B.M.; Shirai, M.; Arai, M. Heck reactions of iodobenzene and methyl acrylate with conventional supported palladium catalysts in the presence of organic and/or inorganic bases without ligands. Chem. Eur. J. 2000, 6, 843-848. [CrossRef]

7. Sekizawa, K.; Widjaja, H.; Maeda, S.; Ozawab, Y.; Eguchia, K. Low temperature oxidation of methane over Pd catalyst supported on metal oxides. Catal. Today 2000, 59, 69-74. [CrossRef]

8. Xiao, L.H.; Sun, K.P.; Xu, X.L.; Li, X.N. Low-temperature catalytic combustion of methane over $\mathrm{Pd} / \mathrm{CeO} 2$ prepared by deposition-precipitation method. Catal. Commun. 2005, 6, 796-801. [CrossRef]

9. Vichaphund, S.; Aht-ong, D.; Sricharoenchaikul, V.; Atong, D. Production of aromatic compounds from catalytic fast pyrolysis of Jatropha residues using metal/HZSM-5 prepared by ion-exchange and impregnation methods. Renew. Energy 2015, 79, 28-37. [CrossRef]

10. Hu, S.; Scudiero, L.; Ha, S. Electronic effect on oxidation of formic acid on supported Pd-Cu bimetallic surface. Electrochim. Acta 2012, 83, 354-358. [CrossRef]

11. Yang, M.M.; Wang, Z.Y.; Wang, W.; Liu, C.J. Synthesis of AuPd alloyed nanoparticles via room-temperature electron reduction with argon glow discharge as electron source. Nanoscale Res. Lett. 2014, 9, 405. [CrossRef]

12. Ouyang, L.Z.; Cao, Z.J.; Wang, H.; Hu, R.Z.; Zhu, M. Application of dielectric barrier discharge plasma-assisted milling in energy storage materials-A review. J. Alloys Compd. 2017, 691, 422-435. [CrossRef]

13. Deng, X.Q.; Zhu, B.; Li, X.S.; Liu, J.L.; Zhu, X.B.; Zhu, A.M. Visible-light photocatalytic oxidation of CO over plasmonic $\mathrm{Au} / \mathrm{TiO}_{2}$ : Unusual features of oxygen plasma activation. Appl. Catal. B Environ. 2016, 188, 48-55. [CrossRef]

14. Di, L.B.; Xu, W.J.; Zhan, Z.B.; Zhang, X.L. Synthesis of alumina supported Pd-Cu alloy nanoparticles for CO oxidation via a fast and facile method. RSC Adv. 2015, 5, 71854-71858. [CrossRef]

15. Gallon, H.J.; Tu, X.; Twigg, M.V.; Whitehead, J.C. Plasma-assisted methane reduction of a NiO catalyst low temperature activation of methane and formation of carbon nanofibres. Appl. Catal. B Environ. 2011, 106, 616-620. [CrossRef]

16. Zhang, J.S.; Di, L.B.; Yu, F.; Duan, D.Z.; Zhang, X.L. Atmospheric-pressure cold plasma activating Au/P25 for CO oxidation: Effect of working gas. Nanomaterials 2018, 8, 742. [CrossRef]

17. Ovanesyan, R.A.; Hausmann, D.M.; Agarwal, S. Low-temperature conformal atomic layer deposition of $\mathrm{SiN}_{\mathrm{x}}$ films using $\mathrm{Si}_{2} \mathrm{Cl}_{6}$ and $\mathrm{NH}_{3}$ plasma. ACS Appl. Mater. Interfaces 2015, 7, 10806-10813. [CrossRef]

18. Guo, Z.F.; Yi, Y.H.; Wang, L.; Yang, J.H.; Guo, H.C. Pt/TS-1 catalyst promoted C-N coupling reaction in $\mathrm{CH}_{4}-\mathrm{NH}_{3}$ plasma for HCN synthesis at low temperature. ACS Catal. 2018, 8, 10219-10224. [CrossRef]

19. Du, C.M.; Ma, D.Y.; Wu, J.; Lin, Y.C.; Xiao, W.; Ruan, J.J.; Huang, D.W. Plasma-catalysis reforming for $\mathrm{H}_{2}$ production from ethanol. Int. J. Hydrog. Energy 2015, 40, 15398-15410. [CrossRef]

20. Xu, W.Q.; Liu, Z.Y.; Johnston-Peck, A.C.; Senanayake, S.D.; Zhou, G.; Stacchiola, D.; Stach, E.A.; Rodriguez, J.A. Steam reforming of ethanol on $\mathrm{Ni} / \mathrm{CeO}_{2}$ : Reaction pathway and interaction between $\mathrm{Ni}$ and the $\mathrm{CeO}_{2}$ support. ACS Catal. 2013, 3, 975-984. [CrossRef]

21. Hou, T.F.; Yu, B.; Zhang, S.Y.; Xu, T.K.; Wang, D.Z.; Cai, W.J. Hydrogen production from ethanol steam reforming over $\mathrm{Rh} / \mathrm{CeO}_{2}$ catalyst. Catal. Commun. 2015, 58, 137-140. [CrossRef] 
22. Wang, B.; Sun, B.; Zhu, X.M.; Yan, Z.Y.; Liu, Y.J.; Liu, H.; Liu, Q. Hydrogen production from alcohol solution by microwave discharge in liquid. Int. J. Hydrog. Energy 2016, 41, 7280-7291. [CrossRef]

23. Wu, Y.W.; Chung, W.C.; Chang, M.B. Modification of $\mathrm{Ni} / \gamma-\mathrm{Al}_{2} \mathrm{O}_{3}$ catalyst with plasma for steam reforming of ethanol to generate hydrogen. Int. J. Hydrog. Energy 2015, 40, 8071-8080. [CrossRef]

24. Di, L.B.; Li, Z.; Zhang, X.L.; Wang, H.Y.; Fan, Z.Y. Reduction of supported metal ions by a safe atmospheric pressure alcohol cold plasma method. Catal. Today 2019, 337, 55-62. [CrossRef]

25. Di, L.B.; Li, Z.; Lee, B.; Park, D.W. An alternative atmospheric-pressure cold plasma method for synthesizing Pd/P25 catalysts with the assistance of ethanol. Int. J. Hydrog. Energy 2017, 42, 11372-11378. [CrossRef]

26. Li, Z.; Zhang, X.L.; Zhang, Y.Z.; Duan, D.Z.; Di, L.B. Hydrogen cold plasma for synthesizing Pd/C catalysts: The effect of support-metal ion interaction. Plasma Sci. Technol. 2018, 20, 014016. [CrossRef]

27. Qi, B.; Di, L.D.; Xu, W.J.; Zhang, X.L. Dry plasma reduction to prepare a high performance Pd/C catalyst at atmospheric pressure for CO oxidation. J. Mater. Chem. A 2014, 2, 11885-11890. [CrossRef]

28. Lazzarini, A.; Piovano, A.; Pellegrini, R.; Leofanti, G.; Agostini, G.; Rudić, S.; Chierotti, M.R.; Gobetto, R.; Battiato, A.; Spoto, G.; et al. A comprehensive approach to investigate the structural and surface properties of activated carbons and related Pd-based catalysts. Catal. Sci. Technol. 2016, 6, 4910-4922. [CrossRef]

29. Di, L.B.; Duan, D.Z.; Park, D.W.; Ahn, W.S.; Lee, B.J.; Zhang, X.L. Cold plasma for synthesizing high performance bimetallic $\mathrm{PdCu}$ catalysts: Effect of reduction sequence and $\mathrm{Pd} / \mathrm{Cu}$ atomic ratios. Top. Catal. 2017, 12-14, 925-933. [CrossRef]

30. Di, L.B.; Zhang, J.S.; Zhang, X.L. A review on the recent progress, challenges, and perspectives of atmospheric-pressure cold plasma for preparation of supported metal catalysts. Plasma Processes Polym. 2018, 15, 1700234. [CrossRef]

31. Fang, G.D.; Dionysiou, D.D.; Wang, Y.; Al-Abed, S.R.; Zhou, D.M. Sulfate radical-based degradation of polychlorinated biphenyls: Effects of chloride ion and reaction kinetics. J. Hazard. Mater. 2012, 227-228, 394-401. [CrossRef]

32. Bao, L.S.; Zhang, X.F.; Yu, L.; Zhu, G.S. Study on the influence of chloride ion content on pavement performance of base material with fly-ash-flushed-by-seawater. Adv. Mater. Res. 2011, 194-196, 993-1000. [CrossRef]

33. Tan, E.Z.; Yin, P.G.; Guo, L. SERS-activity of immobilized silver nanoparticles: Effect of chloride ion. J. Light Scatt. 2010, 22, 305-308. [CrossRef]

34. Hsieh, Y.C.; Senanayake, S.D.; Zhang, Y.; Xu, W.Q.; Polyansky, D.E. Effect of chloride anions on the synthesis and enhanced catalytic activity of silver nanocoral electrodes for $\mathrm{CO}_{2}$ electroreduction. ACS Catal. 2015, 46, 2584-2592. [CrossRef]

35. Di, L.B.; Zhang, X.L.; Lee, B.; Lu, P.; Ahn, W.S.; Park, D.W. Feasibility of atmospheric-pressure CO cold plasma for reduction of supported metal ions. Plasma Chem. Plasma Process. 2017, 37, 1535-1549. [CrossRef] 